\title{
Labyrinthe
}

$6 \mid 2000$

Numéro 6

\section{La police et les alternances politiques (1981-1999)}

\section{Olivier Renaudie}

\section{OpenEdition}

\section{Journals}

Édition électronique

URL : http://journals.openedition.org/labyrinthe/420

DOI : $10.4000 /$ labyrinthe.420

ISSN : 1950-6031

Éditeur

Hermann

Édition imprimée

Date de publication : 1 juin 2000

Pagination : 131-133

Référence électronique

Olivier Renaudie, «La police et les alternances politiques (1981-1999)», Labyrinthe [En ligne], 6 | 2000, mis en ligne le 20 mars 2005, consulté le 01 mai 2019. URL : http://journals.openedition.org/ labyrinthe/420 ; DOI : 10.4000/labyrinthe.420

Ce document a été généré automatiquement le 1 mai 2019.

Propriété intellectuelle 


\title{
La police et les alternances politiques (1981-1999)
}

\author{
Olivier Renaudie
}

\begin{abstract}
Ce texte est la synthèse d'un mémoire de D.E.A. soutenu en septembre 1998 à l'Université Paris II Panthéon-Assas et publié aux éditions PanthéonAssas/LGDJ en novembre 1999.
\end{abstract}

1 Les relations entre le politique et l'administratif font partie des objets d'étude privilégiés de la science politique et de la science administrative. Nombreux sont désormais les travaux ou recherches qui étudient la politisation de la haute fonction publique, l'émergence d'une élite politico-administrative ou l'influence politique des fonctionnaires. Pourtant, Max Weber avait défini les deux principes essentiels qui régissent les relations entre administration et politique. Le premier est celui de la subordination au pouvoir politique : l'administration n'ayant pas de légitimité propre, elle est l'instrument du pouvoir politique auquel elle obéit. Le second principe est celui de la séparation de l'administration et du pouvoir politique : l'administration incarnant la stabilité, la continuité, elle ne peut être liée au pouvoir politique, sous peine de devoir être renouvelée dans sa quasi-totalité en cas d'alternance politique. Mais le modèle weberien n'a jamais été appliqué dans toute sa rigueur : " partout les fonctionnaires s'appuient sur les ressources spécifiques dont ils disposent pour exercer une influence sur les affaires publiques, et les relations avec le politique sont à la base d'interdépendance

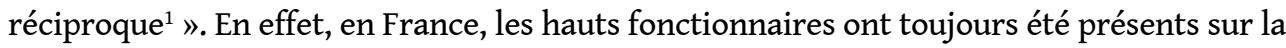
scène politique et les considérations partisanes ont toujours été importantes dans l'affectation aux emplois de responsabilité, la création de l'École Nationale d'Administration n'ayant fait que favoriser ce processus d'osmose entre les élites politiques et les élites administratives.

2 Cette idée d'osmose politico-administrative s'applique de manière très particulière à la police. Si l'on définit la fonction policière comme consistant à assurer la régulation interne d'une société globale et le respect d'un certain nombre de règles qui la régissent 
par le recours éventuel à des interventions coercitives faisant appel à l'usage de la force, le rapport de celle-ci avec l'organisation politique est évident : toute organisation politique comporte une dimension policière et la fonction policière apparaît comme consubstantielle à l'organisation politique d'une société. Cette consubstantialité est confirmée par la considération traditionnelle du pouvoir de police comme étant un " pouvoir régalien », un attribut fondamental de l'État. Elle est également confirmée par la situation originelle des rapports entre police et politique qui est celle d'une confusion : le concept de police impliquant « une virtualité de compétences pouvant se multiplier et s'étendre selon les besoins ${ }^{2}$ ", il permet de qualifier le rôle même de l'État.

3 Si cette position privilégiée de l'institution policière dans le champ politique conditionne les rapports entre celle-ci et le politique, elle a également des conséquences sur les relations entre la police et la politique. Ces relations ont pour base un paradoxe : le pouvoir politique utilise la police comme exécutant de ses décisions et comme instrument d'information mais, bien loin de n'être qu'un simple instrument, la police est dotée d'un pouvoir d'appréciation important et d'une dynamique propre $^{3}$. Cette question de l'autonomisation de la police a conduit les gouvernants à renforcer leur influence sur elle, la faisant ainsi basculer dans le champ de la politique. C'est ce que révèle l'étude de l'institution policière à travers les alternances politiques.

4 Les alternances politiques permettent de mesurer le degré de pénétration de la politique dans la police ; les relations d'interdépendance deviennent alors plus visibles, plus lisibles. Cela est illustré principalement par la forte emprise politique sur le processus de désignation des responsables policiers (cabinet, directions et services centraux, Préfecture de police). Mais renouveler la haute hiérarchie policière lors d'une alternance politique ne garantit pas l'application efficace des politiques, c'est pourquoi le ministre de l'Intérieur est toujours à la recherche d'un relais au sein de l'institution. Ce relais a longtemps été constitué par les syndicats, notamment la puissante Fédération autonome des syndicats de police (FASP) avec qui la gauche avait d'évidentes affinités idéologiques ; la FASP faisant aboutir nombre de ses revendications, on a pu parler d'une véritable cogestion de la police entre le ministre et les syndicats. Cette situation n'a cependant pas duré. D'une part, le syndicalisme policier est entré dans une dynamique de crise. D'autre part, l'Institut des hautes études de la sécurité intérieure (IHESI), créé par Pierre Joxe en 1989, est venu supplanter les syndicats pour la production et l'application de la doctrine policière. Il en est résulté un consensus politique à propos de la police, fondé sur le concept de sécurité intérieure. Ainsi l'option actuelle en faveur d'une police de proximité pourrait aussi bien être celle d'un gouvernement de droite.

Ce consensus politique n'a pas pour autant entamé la capacité de résistance au changement de l'institution policière. Cela, d'ailleurs, ne doit pas être sans interroger le politique sur la nature des fonctions qu'il remplit auprès de ce qu'il croit être son instrument. La politisation des hauts emplois de la hiérarchie policière est une apparence : le politique ne semble pas celui qui est à l'origine des politiques, il n'est pas non plus celui qui les légitime. 


\section{NOTES}

1. Jacques Chevallier, «L'élite politico-administrative : une interpénétration discutée », Pouvoirs, $n^{\circ}$ 80, 1997, p. 90.

2. Pierre Legendre, Histoire de l'administration de 1750 à nos jours, Paris, PUF, 1968, p. 246.

3. C'est ainsi que Dominique Monjardet évoque un processus d'" inversion hiérarchique » pour décrire le fonctionnement de l'institution policière (Ce que fait la police. Sociologie de la force publique, Paris, La Découverte, 1996, p. 88-95).

\section{AUTEUR}

\section{OLIVIER RENAUDIE}

Olivier Renaudie est allocataire-moniteur à l'Université Paris II. Titulaire d'un D.E.A de droit public et d'un D.E.A. de science administrative, il prépare une thèse de doctorat sur La Préfecture de police de Paris. 